\title{
EL PINTOR ALONSO LÓPEZ DE HERRERA*
}

\section{Por Manuel Romero de Terreros}

El bachiller Arias de Villalobos, poeta de renombre en su tiempo, publicó en México, en el año de 1623, una conceptuosa descripción de la Jura de Felipe IV, con el aparatoso título de Obediencia que México, cabeza de la Nueva España, dio a la Majestad del Rey D. Felipe de Austria, $N$ (uestro) $S$ (eñor), alzando pendón de vasallaje en su Real nombre.-Con un discurso en verso, del estado de la misma Ciudad, desde su más antigua fundacion, imperio y conquista, hasta el mayor del crecimiento y grandeza en que hoy está. ${ }^{1}$ Este discurso en verso, escrito por cierto veinte años antes, lo intituló Mercurio y se reduce, como dice don Jenaro García, "a un canto descriptivo del estado y grandeza de la Ciudad de México" en aquella época, si bien, añadimos nosotros, de un estro poco feliz.

Al referirse a las numerosas iglesias que ya para entonces habia en la metrópoli, dice Arias de Villalobos lo siguiente:

"Vamos a los retablos de su frente, De Apeles y Parrasios propios nuestros;

Aquí el relieve y el pincel valiente

Vuelan a lo inmortal por sus maestros;

Del arte, en suma, son la esencia y ente, Y muertos, y entre vivos, los más diestros, Requena, Vázquez, Rúa, Prado, Herrera, Franco, Echave, Perín, Concha y Pesquera".

Y explica, en nota, que estos artistas fueron "Pintores y escultores, ya muertos, y vivos, que en este Reino han sido extremados en los retablos de templos".

- Este trabajo fue publicado hace años: El pintor Alonso López de Herrera. México, Edit. Cultura, 1934. Por la rareza del folleto y por su interés se ha pensado que es conveniente reproducirlo en una segunda versión corregida y aumentada por el autor.

1 Documentos inéditos o muy raros para la Historia de México, publicados por Jenaro García, tomo xIr. México en 1623, por el bachiller Arias de Villalobos. México, 1907. La reimprimió don Jenaro García del único ejemplar que se conoce y que se conserva en la Biblioteca Lafragua, en el Colegio del Estado de Puebla. 
Pocas noticias hay de Vicente de Requena y Tomás de Prado, pintores; y de Diego Pesquera, escultor.

En cuanto a los demás artistas que menciona Arias de Villalobos -con excepción de Herrera- a pesar de ser muy conocidos en la historia de la pintura colonial, nos atrevemos a recordarlos brevemente. ${ }^{2}$

Juan de Rúa o de Arrúe, nació en 1565 en las provincias de Avalos y descendía, por línea materna, del infortunado rey tarasco Caltzontzin. Fue discípulo de Andrés de Concha y alcanzó gran fama como pintor. A fines del siglo xvi se estableció en Puebla y más tarde residió por algún tiempo en Oaxaca. En ambas ciudades y en los pueblos comarcanos trabajó Arrúe en la pintura de altares, como en el retablo de la iglesia de Etla y en los cuadros de la Vida de la Virgen, en la de San Francisco de Cuauhtinchán. En 1621, ejecutó parte de los adornos del túmulo para las honras de Margarita de Austria, que se solemnizaron en el convento de Santo Domingo. Testó en Puebla en el año de 1637 y debe haber fallecido poco después.

Alonso Vázquez, célebre pintor sevillano, después de haber exornado con excelentes pinturas claustros e iglesias de su ciudad natal, se trasladó a México a principios del siglo xvir y falleció aquí en 1608 . Según José de Ibarra, pintor del siglo xviII, Alonso Vázquez "introdujo muy buena doctrina" en la pintura colonial. De sus obras, ejecutadas durante los pocos años que vivió en México, se sabe que pintó los cuadros del altar mayor de la antigua Universidad, ofrecidos por el virrey Marqués de Montesclaros, y el Martirio de Santa Margarita, que había en el Palacio de los Virreyes.

Alonso Franco fue dibujante de cierta habilidad, si hemos de juzgar por el retrato de Arias de Villalobos, dentro de un marco de típicos ornamentos barrocos, que diseñó en 1604, y el cual fue grabado por Samuel Stradamus y publicado en México, en la imprenta de Diego Garrido, al frente de la Obediencia cuya estrofa venimos glosando.

Baltasar de Echave, llamado "el Viejo", para distinguirlo de su hijo y nieto de los mismos nombre y apellido, que también fueron pintores, es quizás el artista más conocido de la época colonial; su fama es muy merecida por las numerosas y magníficas pinturas que legó a la posteridad.

Simón Pereyns, de origen flamenco, vino a México en 1566 con el tercer virrey, don Gastón de Peralta, Marqués de Falces, y pintó varias de las obras que exornaron los retablos de la antigua Catedral de Méxi-

2 Véase Arte Colonial en México, por Manuel Toussaint. México, 1962. 
co. En la actual se conservan, de su pincel, un San Cristóbal y la famosa Virgen, llamada del Perdón, que está sobre el altar de este nombre. También ejecutó las pinturas del retablo mayor de la iglesia franciscana de Huejotzingo. En cierta ocasión Simón Pereyns fue procesado por el Santo Oficio, por haber dicho que prefería hacer retratos a pintar santos.

Andrés de la Concha figuró a fines del siglo xvi y obtuvo fama de gran pintor. Doró el retablo mayor de la Catedral vieja de México, y para el túmulo de las honras de Felipe II pintó dos cuadros: La Fama y La Victoria. Las únicas pinturas auténticas de Andrés de la Concha que actualmente existen son las del retablo principal de la iglesia de Santo Domingo de Yanhuitlán, Oaxaca.

Alonso López de Herrera -para darle su nombre completo- indudablemente uno de los pintores más notables del México virreinal, quedó casi olvidado. Apenas si el doctor Lucio lo menciona en su Reseña histórica de la pintura mexicana de los siglos xvII y xvin, y lo mismo hace don Bernardo Olivares, en sus apuntes sobre la pintura colonial en Puebla.

López de Herrera nació en la ciudad de México, como lo comprueba su fe de bautismo, que obra en el archivo de la parroquia de la Santa Veracruz y que reza así:

En veynte y quatro de hebre de mill y quiz y setenta y nueue as el $p^{*}$ Garcia Rodriguez baptizo en el monasto de Regina con lica del $S^{\circ}$ prouisor a Alonso hijo de Ju lopez de herrera y de madalena lopez su muger vezinos desta parrochia fueron sus padrinos Gonzalo mendez y fran ${ }^{c^{\mathbf{a}}}$ de palacios su muger vecinos de mexico. Bart ${ }^{\mathrm{m}^{*}}$ de frade.Rúbrica.

Pero casi nada se sabe de cierto de su familia. Don Ignacio Rubio Mañé, en el discurso sobre "Los primeros vecinos de la Ciudad de Mérida de Yucatán", que pronunció al ingresar en la Academia de la Historia, dice que "el Adelantado Montejo tuvo también varios parientes suyos por afinidad que fueron vecinos de Mérida: Alonso López de Herrera, que le tocó el solar que hace esquina noroeste de la plaza de armas. Pero no arraigó. No hemos encontrado ni matrimonio ni rasgo suyo de haberse quedado. Era hermano de doña Beatriz, la esposa del Adelantado, y tal vez, al descender éste del gobierno en 1549, se desavecindó de Mérida".

¿Se trasladaría a México este Alonso López de Herrera? Lo cierto es que en el Archivo General de la Nación, obra un documento, entre 
los expedientes de la antigua Inquisición, en que consta que, a fines del año de 1571, se hizo saber al arzobispo Moya de Contreras que don Fulgencio de Vique, abogado de la Real Audiencia, había denunciado a un Alonso López de Herrera, Escribano Real; ante el Juez Ordinario Eclesiástico, por haber pronunciado "palabras mal sonantes, erróneas o de mal sentido". El proceso no se siguió, de manera que no arroja más luz sobre el particular. ¿Sería el yucateco el denunciado al Santo Oficio? ¿Sería hermano de Juan López de Herrera y, por lo tanto, tío de nuestro pintor? Tal vez.

Es cosa segura que Alonso López de Herrera ejerció su arte, además de en México, en Puebla de los Ángeles; y hay fundamento para creer que pintó también en Valladolid de Michoacán (hoy Morelia) y aun en Oaxaca. ${ }^{3}$

La fecha exacta de la muerte de nuestro pintor no se conoce. Toussaint opina fundadamente que debe haber ocurrido antes de $1654 .^{4}$

La primera obra suya, firmada, que se conoce es el excelente retrato de fray García Guerra, existente en el Museo Nacional de Historia, en Chapultepec. Representa al célebre Arzobispo de México y posteriormente Virrey de la Nueva España, de cuerpo entero y de tamaño natural, y ostenta al pie una cartela con esta leyenda: Dominus Fr. Garcias Guerra Archiepiscopus Mexicanus Assumptus Ex Predicatorum Familia oriundus ex oppido Fromestano. Clientulus tuus Yllustrissime Princeps Yldephosus Lopez a Herrera non tuas virtutes clarisimas (sic) ced (sic) illustrem tanti principis excudit imaginem 1609, la cual puede traducirse así: "El Señor Don Fray García Guerra, Arzobispo de México, escogido de la Orden de Predicadores, natural de la rica Frómista.-Tu adicto, Ilustrísimo Señor, Alonso López de Herrera, retrató, no tus clarísimas virtudes, sino tu efigie, ilustre por la estirpe de semejante príncipe, $1609^{\prime}$. Es un magnifico retrato, tomado evidentemente del natural y no-

3 Don Manuel Toussaint opina que bien pueden haber sido obra de López de Herrera "las pinturas al óleo que adornan la parte interior de los soportes en el claustro del Convento de Santo Domingo en Oaxaca". Véase "Cuadros desconocidos de Alonso López de Herrera", en Anales del Instituto de Investigaciones Estéticas, No 12. México, 1945.

4 Articulo citado. 


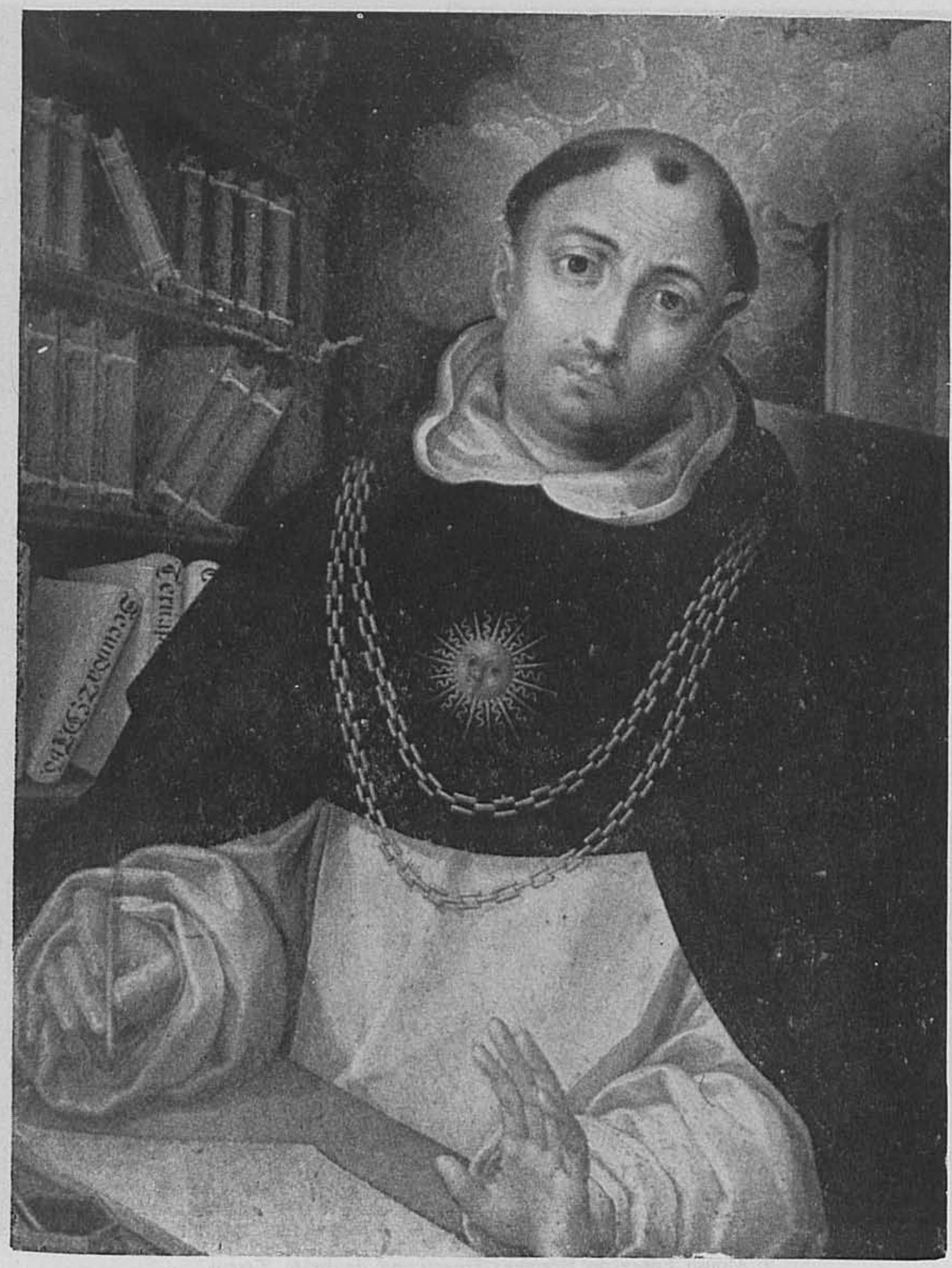

- 1. Alonso López de Herrera. Santo Tomis de Aquino. 
DOI: http://dx.doi.org/10.22201/iie.18703062e.1965.34.800

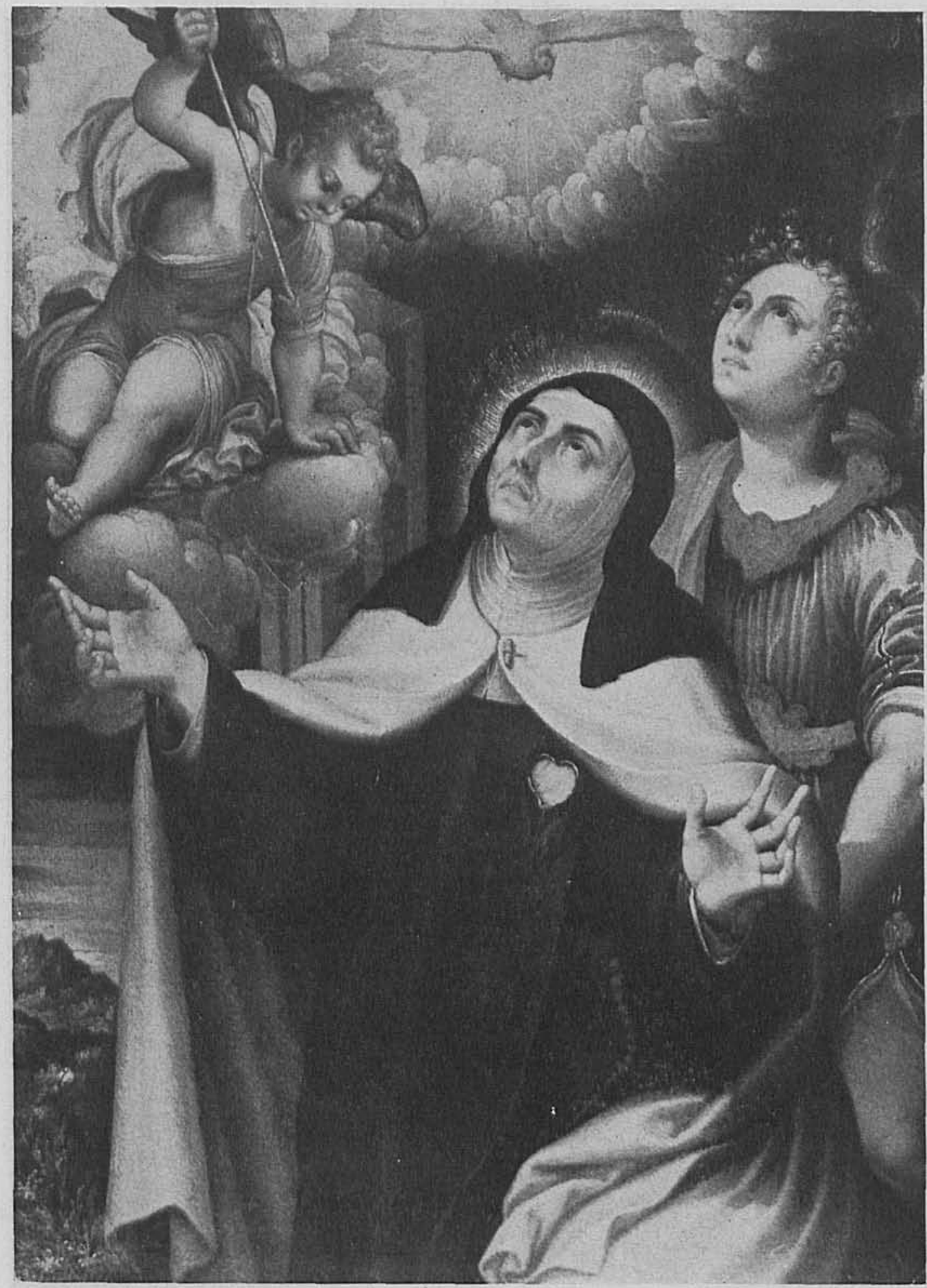

2. Alonso López de Herrera. Transfixión de Santa Teresa. . 


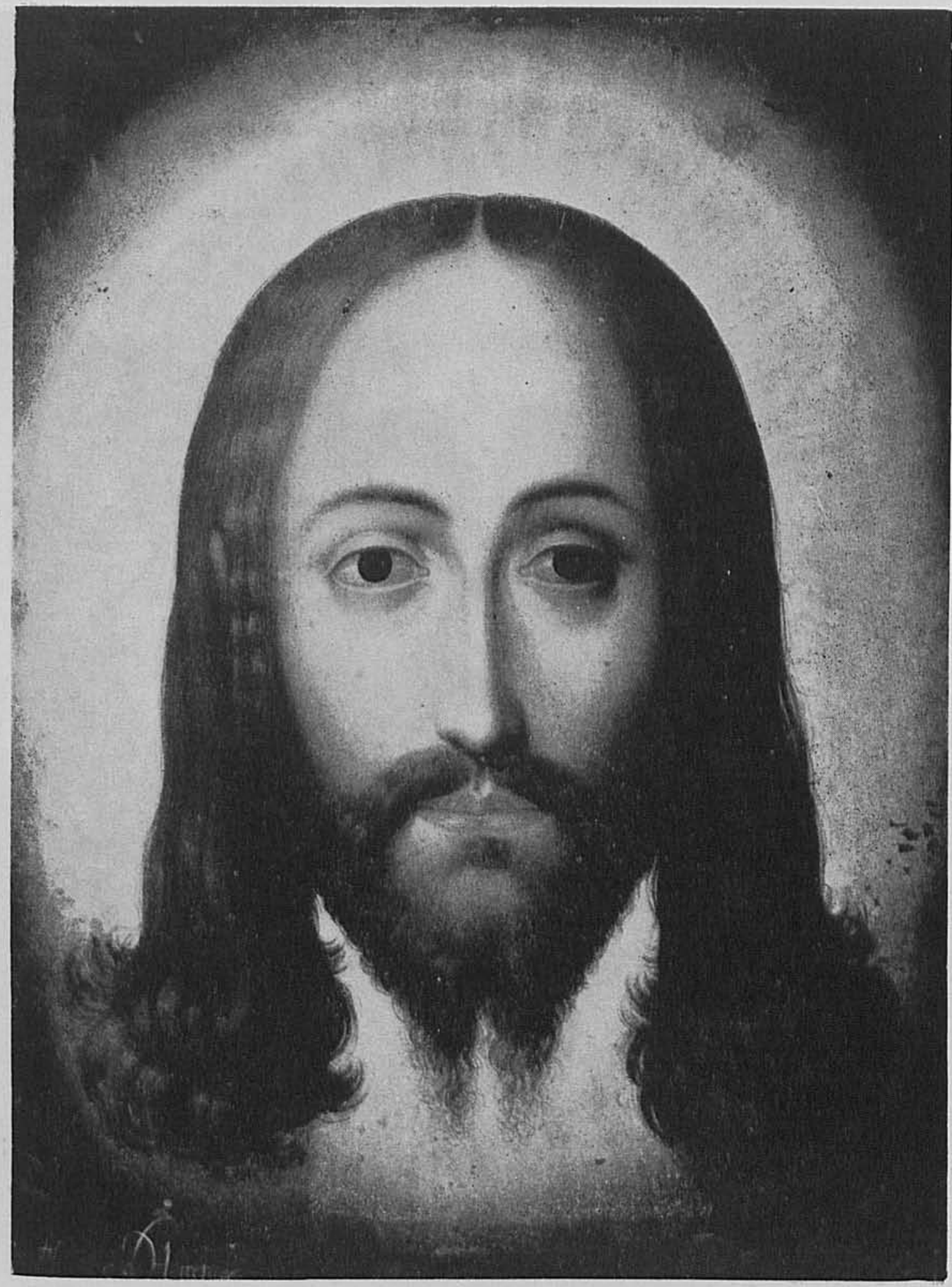

3. Alonso López de Herrera. La Santa Faz, 
DOI: http://dx.doi.org/10.22201/iie.18703062e.1965.34.800

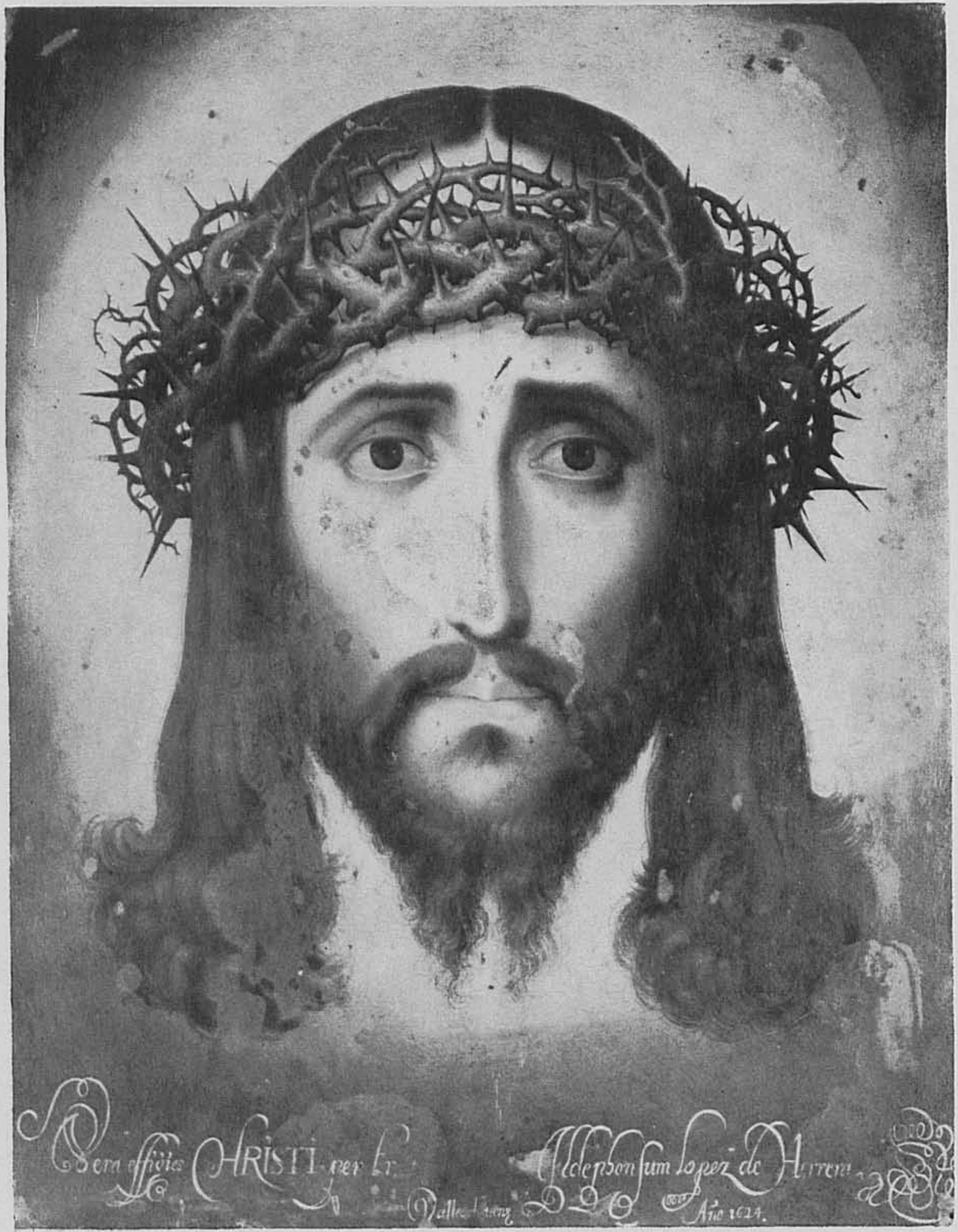

4. Alonso López de Herrera. La Santa Faz. 1624. 
DOI: http://dx.doi.org/10.22201/iie.18703062e.1965.34.800

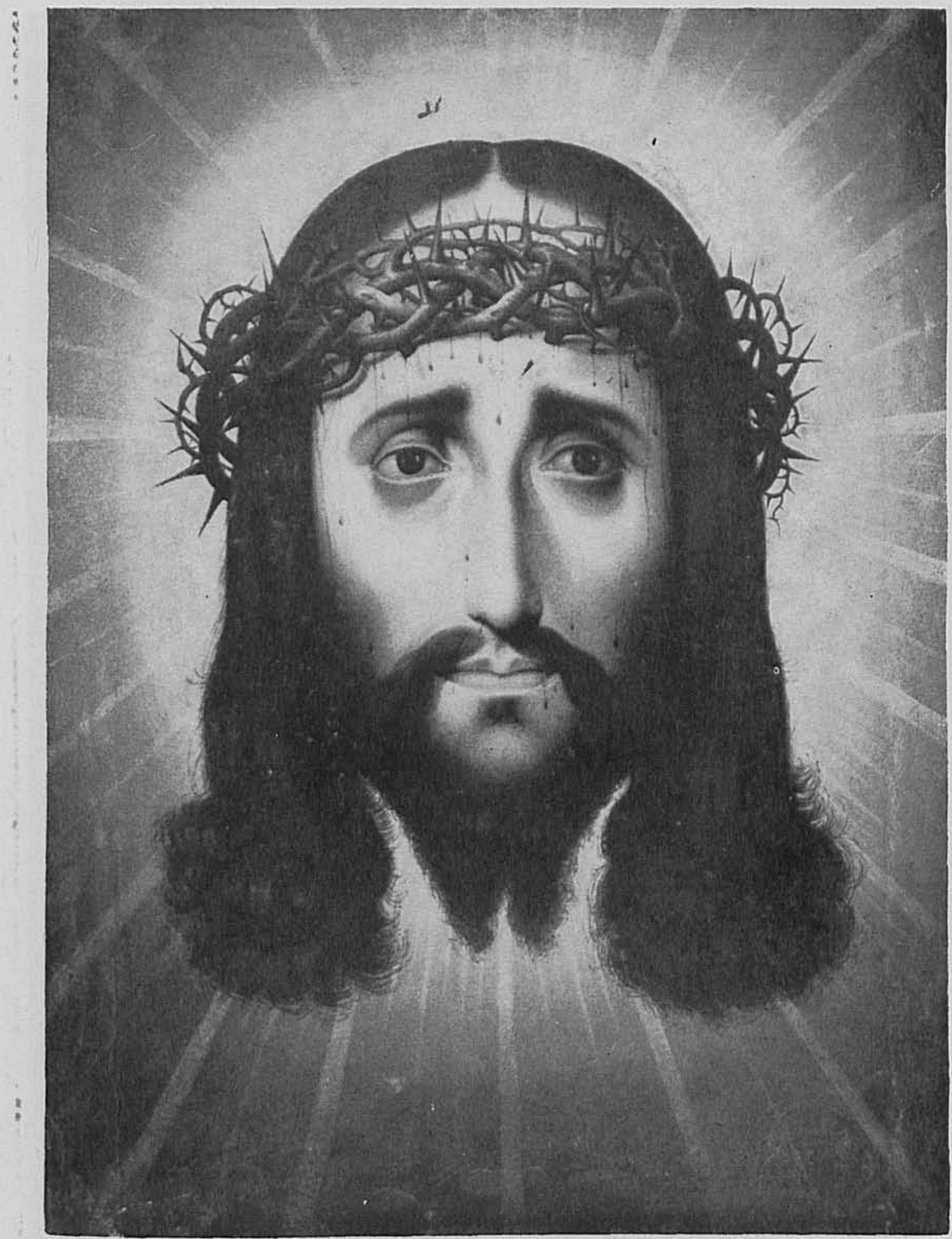

5. Alonso L.ópez de Herrera. La Santa Faz. 


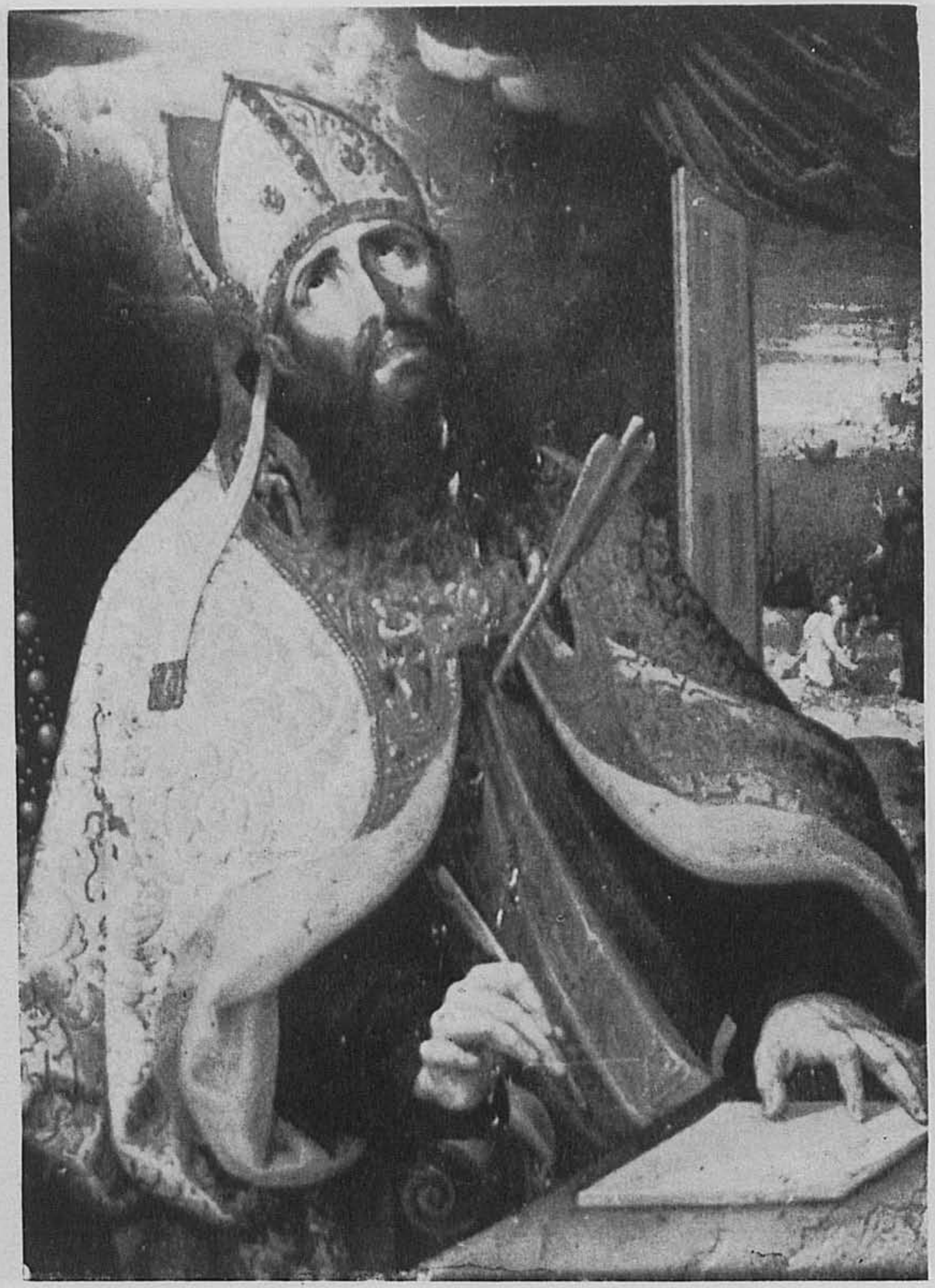

6. Alonso López de Herrera. Extasis de San Agustin. 
DOI: http://dx.doi.org/10.22201/iie.18703062e.1965.34.800

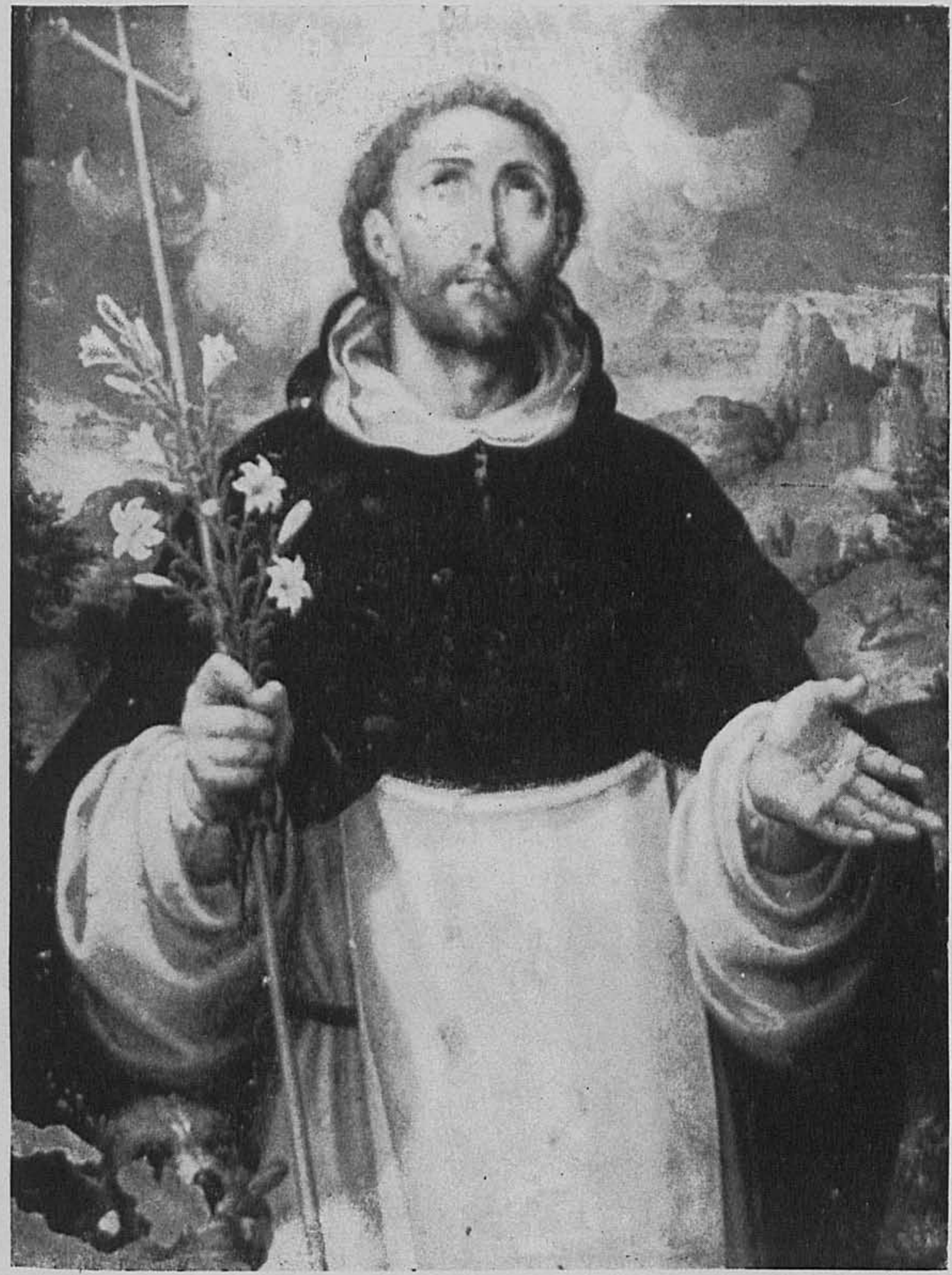

7. Alonso López de Herrera. Extasis de Santo Domingo. 


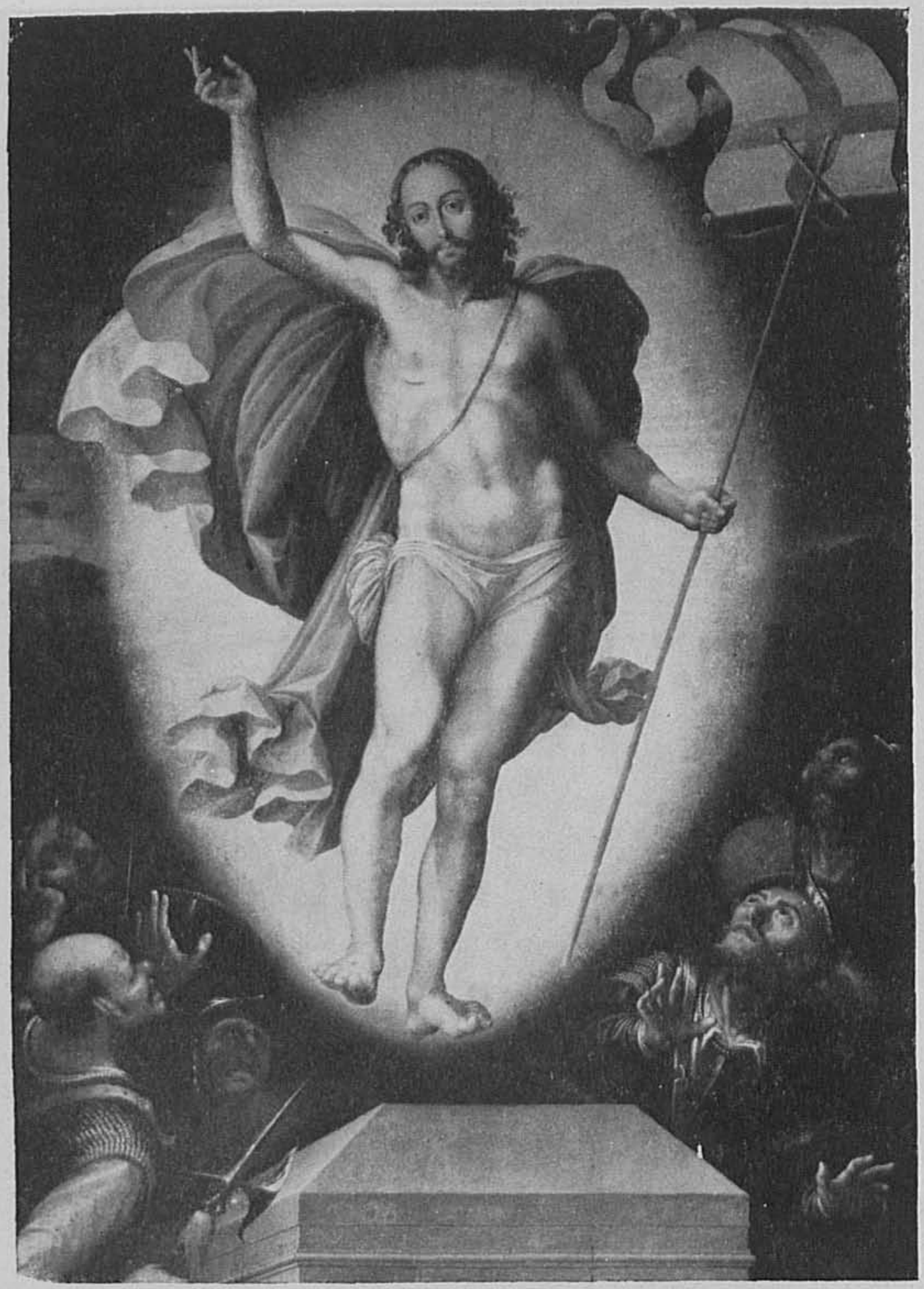

9. Alonso López de Herrera. La Resurrección. 1622 (?) 


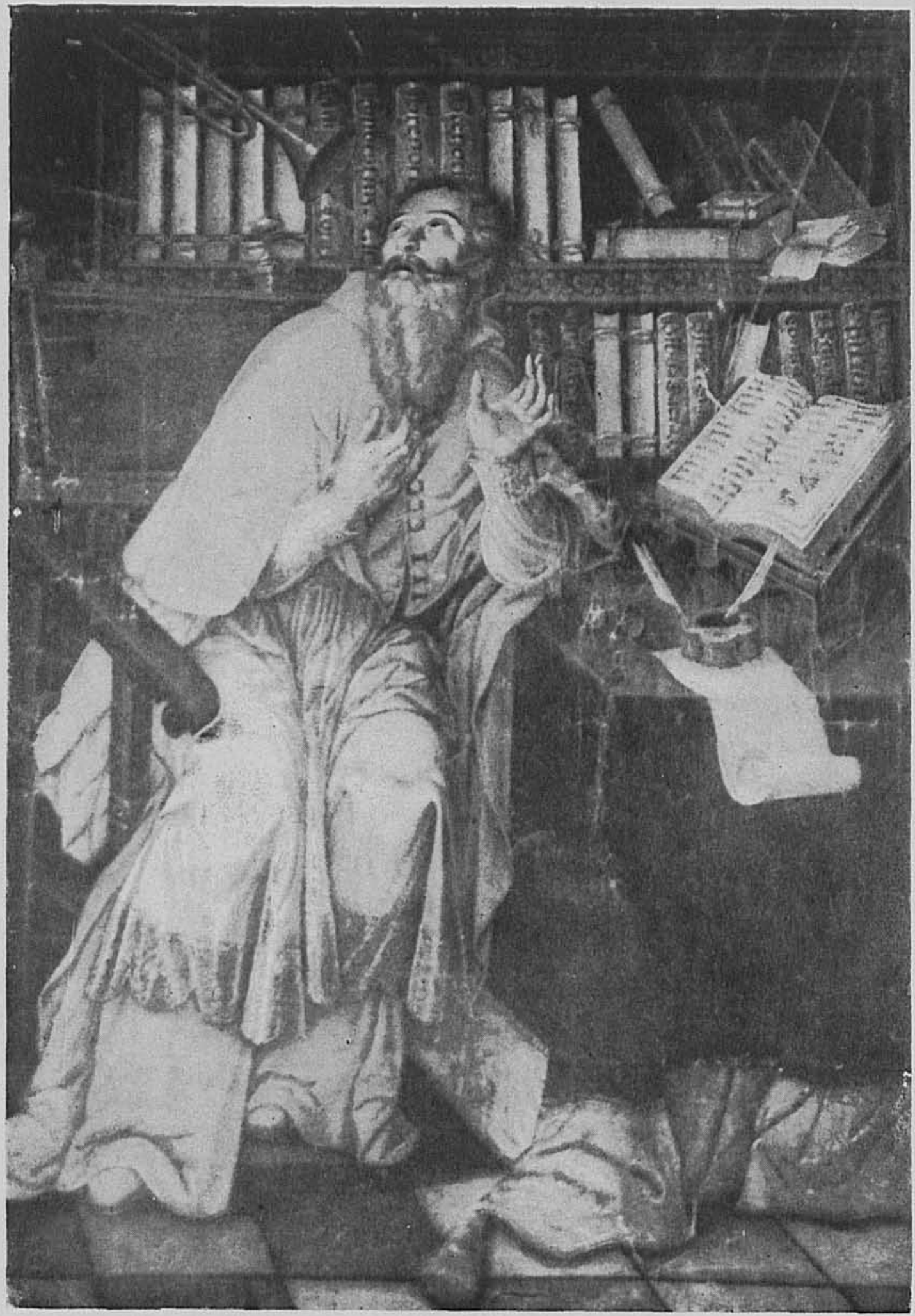

10. Alonso López de Herrera. San Jerónimo. 


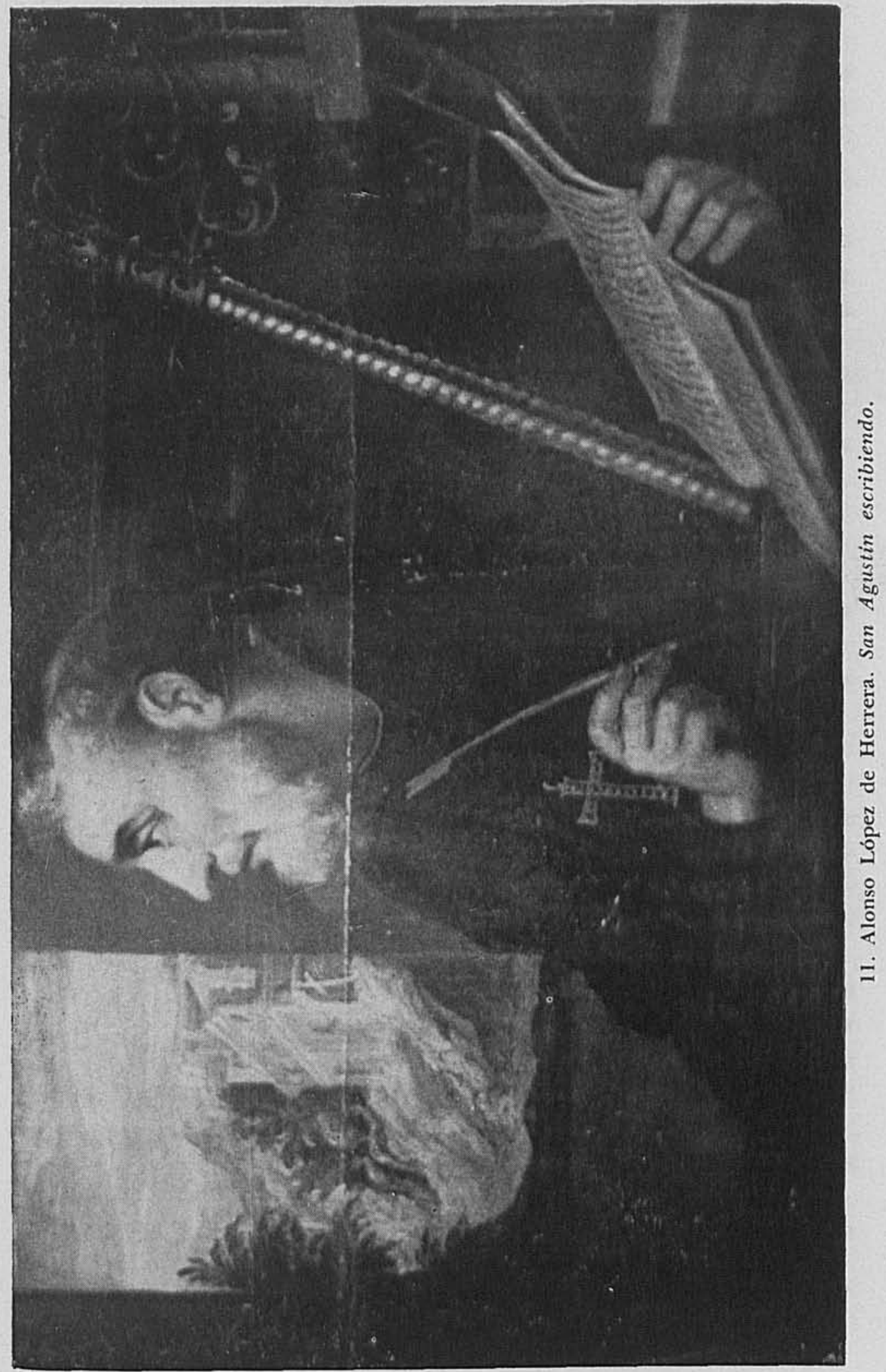




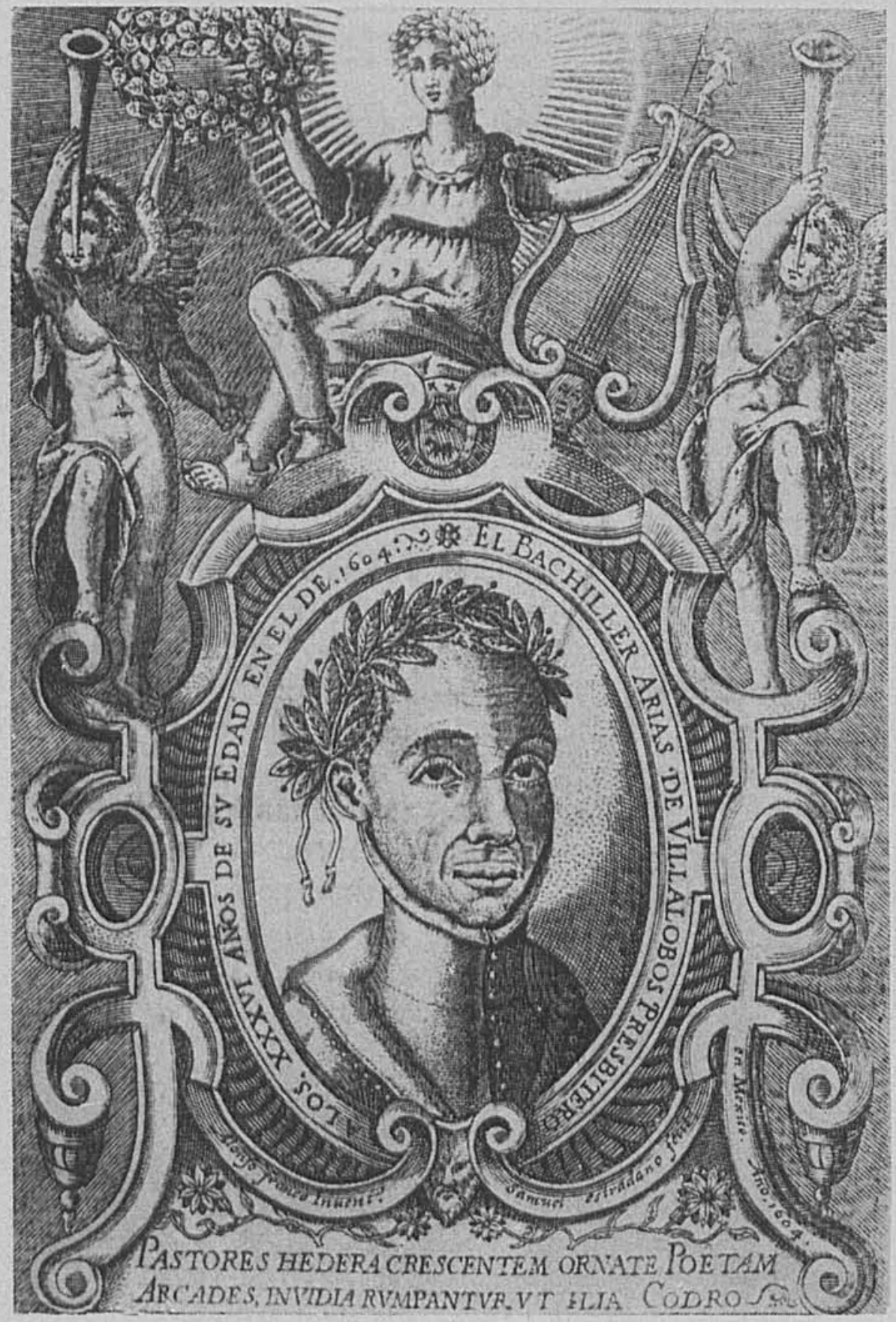

12. Arias de Villalobos. Dibujo de Alonso Franco. Grabado en cobre de Samuel Stradamo. México, 1604. 
table por la acuciosa fidelidad con que están tratados todos los accesorios. 5

El que esto escribe posee una hermosa lámina, que representa a Santo Tomás de Aquino, la cual, si en lo general ofrece grande semejanza con el retrato de fray García Guerra, en algunos detalles presenta identidad absoluta. Es lógico, pues, deducir que la pintó López de Herrera. Este cuadro tiene la particularidad de haber sido pintado al dorso de un trozo de lámina de cobre que sirvió con anterioridad para el grabado de una serie de pequeñas figuras, de busto, todas muy parecidas, que pretenden representar a las esposas de los emperadores romanos. Quizás este grabado sea del buril de Samuel Stradamus.

De la misma mano de López de Herrera existen, en una colección particular, una lámina que representa la Transfixión de Santa Teresa, ${ }^{\circ}$ pintura hermosa en grado sumo y de escorzos bien resueltos; y, en las colecciones de la antigua Academia de San Carlos, otra de la Santa Faz, firmada, que ofrece a su vez grandes semejanzas con la de Santo Tomás de Aquino, puesto que la nariz, los labios y los ojos de ambos rostros son de idéntica factura.

Pero nos inclinamos a creer que esta Santa $F a z$, por su más esmerada ejecución, es posterior a la que pintó en Puebla, y existe hoy en aquella Catedral, que ostenta, detrás de la cabeza, tres brazos de la Cruz de la Orden de Santo Domingo.

También en Puebla pintó López de Herrera un hermoso Divino Rostro, al óleo sobre tela, de 0.45 por 0.35 , que hoy forma parte de la colección Pérez de Salazar. Por cierto que esta pintura es casi idéntica a otra, en lámina de cobre, que lleva en la parte inferior, en letra extraordinariamente exornada, esta leyenda: Vera effigies CHRISTI per Ildephonsum Lopez de Herrera. -Vallesolitane.- Año de 1624, lo que indica que en esa fecha se hallaba el pintor en la actual Morelia.

Diez años más tarde, pintó el Divino Rostro, con enorme corona de espinas, que hiere no solamente la frente del Señor, como las otras, sino toda su cabeza, existente hoy en el "Altar del Perdón", de la Catedral de México. Esta lámina, lleva en la parte inferior, la leyenda: $A$ devo. cion De ffranco de Baeza.-Fr. Alo. de Herrera, 1634.

Ahora bien, si se compara la Santa Faz de la Academia con estos

5 En este retrato estí inspiraclo el de busto que figura en la colección iconográfica de virreyes en el Museo de Chapultepec; pero es de muy distinta mano.

- La lámina tiene una perforación en forma de corazón, que se hizo seguramente para colocar en ella alguna reliquia. 
Divinos Rostros, se verá que la nariz, boca, barba y cabellos de las cuatro pinturas son parecidísimos hasta en los menores detalles, y solamente varía el colorido y la expresión de los ojos, pues si en la Santa Faz la mirada es impasible, como en un icono bizantino, los Divinos Rostros, en cambio, coronados de espinas y manchados de sangre y lágrimas, expresan el más agudo dolor.

Hay otra lámina, de propiedad particular, que representa las medias figuras, por un lado, de San Agustín y, por el otro, de Santo Domingo, ambos en éxtasis. Es bellísima, está firmada Fr. Alo. de Herrera $162 \ldots$, y ofrece todas las caracteristicas de nuestro pintor.

El hecho de que estas láminas estuvieran firmadas por Fray Alonso de Herrera fue claro indicio de que el pintor del retrato de García Guerra entró posteriormente en religión; pero quedaba por aclarar en qué Orden habia profesado.

Sospechamos desde un principio que tuviera López de Herrera grande simpatía por la Orden de Predicadores, dado el cariño, si se nos permite la frase, con que había pintado a Santo Tomás de Aquino, a fray Garcia Guerra y a Santo Domingo de Guzmán.

$Y$ efectivamente, encontramos que fray Alonso Franco, en la Segunda parte de la historia de la Provincia de Santiago de México, al hablar de la gestión del prior fray Benito de Vega, por los años de 1622, dice lo siguiente: "Quando se fabricó la iglesia de Santo Domingo de México se trajo de España retablo grande para el altar mayor, mas como las cosas se van perfeccionando con los dfas ya era obra antigua y no parecía como quando se puso. Determinóse el Prior fray Benito de Vega y buscó los mejores maestros, assí escultores como ensambladores, doradores y estofadores que tenía la Nueva España, y dentro del Conuento de México hiço hacer vn retablo grande para todo el testero de la capilla mayor, tan excelente y primoroso que es la cosa mejor de esta materia que hay en Nueua España, y no inferior a otro de los de España. Animóle mucho al Padre Prior fray Benito hauer dado el hauito en aquel Conuento y ser actual nouicio vn gran pintor llamado fray Alonso de Herrera, superior maestro en la pintura. Este nouicio pintó los tableros que hay de. pintura, cosa excelentísima y curiosa, y assí salió perfectíssima esta obra, y en menos de dos ańos se acauó". ?

Subsistió este retablo hasta el año de 1716, en que, por haberse anega-

7 Fray Alonso Franco. Segunda parte de la Historia de la provincia de Santiago de México, Orden de Predicadores, en la Nueva España. México, Museo Nacional, 1900. Pp. 392-3. 
do la iglesia antigua, se hizo preciso construir una nueva, que es la que actualmente vemos. Es muy probable que se aprovecharan las pinturas de Herrera para el nuevo retablo, pero éste desapareció definitivamente, a principios del siglo xix, cuando cedió su puesto al actual altar mayor que erigió don Manuel Tolsá.

A nuestro pintor alude seguramente el citado cronista, cuando escribe más adelante que, deseando tener una copia de la imagen de Santo Domingo de Soriano, el Provincial fray Juan de Córdoba (1642) "a un Religioso nuestro, gran pintor, que estaua en el Conuento, le ordenó que pintase en tablero vn retrato de nuestro Padre Santo Domingo, de cuerpo entero, en pie y de la manera y modo que se decía en la Relación, en el tamaño del cuerpo, en el modo del hauito, y en tener vn libro en la mano derecha, leuantado, y en la izquierda el ramo de açucenas, y que esta pintura fuesse lo principal del retablo que se hacía; y en lo alto de él se pintase en tabla la Reina del cielo dando el lienço de Santo Domingo al Religiosso, asistiendo a esta acción las Santas Marfa Magdalena y Catarina virgen y mártir". 8

No era esta la primera vez que López de Herrera pintaba a Santo Domingo de Soriano: hay en la iglesia de Churubusco, en un retablo procedente de la antigua y hoy inexistente iglesia de Dominicos de Ia Piedad, un lienzo que representa al Santo, de medio tamaño natural, tal como lo describe el padre Franco, y con la siguiente leyenda al pie, dentro de un óvalo decorativo:

Retrato de la Milagro/sa Imagen, de Nro. Pe.Sto/Domingo de Guzman que/está en Soriano, en Italia fue/traida por mano de la Virgen/ Na. Sa. y de Sta. Maria Magda/lena, y de Sta. Catharina/Martir. Sucedió, a 15 de Se/tiembre el año de 1530. Por/mano del P. fr. Ao. de Herre/ra 1637. Presenta todas las características de nuestro pintor, pues, por decirlo así, López de Herrera solía copiarse a sí mismo con frecuencia. Desgraciadamente, esta pintura no se encuentra en buen estado de conservación y hasta parece que ha sufrido algunos retoques.

Fray Manuel Antonio Moxica, en su obra Tesoro escondido en el delicioso campo ... del Noviciado de los Frailes Predicadores... de México, después de enumerar los religiosos dominicos, insignes en virtud y

8 Ibidem., p. 550. Quizás esta imagen sea la misma que hasta la fecha existe en uno de los retablos antiguos de la iglesia de Santo Domingo; tiene pie esta leyenda: Retrato de la milagrosa y celestial Imagen de Sto. Domingo q esta en Soriano: fue traida por mano de la Virgen SSma. y Sa. Maria Magdalena y Sta. Catarina Martir. Año de 1530. A 15 de Setiembre. No está firmada. 
letras, de la provincia de México, añade: "Y para que no falte de todo, aun en inferiores aprovechamientos, respeto de las letras, tuvimos un Apeles en sus dedos, en el nombre Fr. Alonso López de Herrera, hoy en la voz de todos divino; hoy todavía goza de este predicado, habiendo mucho tiempo que murió este Sugeto: pues luego que se vé una buena pintura, se dice que será del divino Herreva". ${ }^{\circ}$

Esta aseveración del padre Moxica, en nuestro sentir, pone de manifiesto la confusión que ha habido y el error que ha venido repitiéndose, desde que don José Bernardo Couto escribió su Diálogo Sobre la Historia de la Pintura en México, en que dice que se dio el nombre de divino a Juan de Herrera, autor de los pequeños cuadros en las puertas de las gavetas de la Capilla de las Reliquias en la Catedral de México, cuadros que no carecen de mérito, ciertamente, pero que son muy inferiores a cualquiera de las pinturas de Alonso López de Herrera. ${ }^{10}$

La obra maestra de nuestro pintor fue indudablemente el cuadro de la Asunción de Maria que se exhibia en las Galerías de la antigua Academia de San Carlos, y que tradicionalmente se atribuía a Alonso Vázquez.

En opinión de varias personas entendidas en la materia, csta bellísima pintura fue ejecutada por la misma mano que las láminas de Santo Tomás de Aquino y la Transfixión de Santa Teresa -es decir, por Alonso López de Herrera-, dados su factura, su empaste y diversos detalles que en los tres cuadros son idénticos. Admíranse en la Asunción de Maria, una excelente composición, un brillante colorido, habilisimos escorzos, y verdadera maestria en el dibujo de las manos. Está pintada en tabla y es de grandes dimensiones, puesto que los personajes que representa son de tamaño natural. $Y$ claramente se ve que el pintor tuvo especial empeño en hacer resaltar la diferencia que hay entre la parte superior de su obra y la inferior, es decir, entre la figura ideal de la Virgen que asciende a los cielos rodeada de ángeles y querubines, y los mortales - gente, si se quiere, hasta vulgar- que quedan

- Tesoro escondido en el delicioso campo, ameno huevto, florido vergel y fragante pensil del Noviciado de los Frayles Predicadores de esta Provincia de Santiago de México. Reimpreso en México. José Fernández de Jáuregui, 1799, p. 43. Ni León ni Medina describen la primera edición; Cabrera Quintero, en su Escudo de Armas de México, dice que se escribió en 1712 y que en su tiempo el libro era "más escaso que debiera".

10 Aclara este punto Manuel Toussaint en una nota, al pie de la página 76, de la magnífica edición del Dirilogo de Couto, que publicó en 1947. 
en tierra admirando el prodigio. Los tonos cálidos del cuadro y algunas de sus figuras recuerdan al Ticiano y al Veronés; y quizás la composición no haya sido del todo original, pues es muy probable que López de Herrera se haya inspirado, como casi todos los pintores de su época, en los grabados de cuadros europeos que solían venir a la Nueva España.

La Resurrección de Cristo, que hace algunos años perteneció a don José Vázquez Tagle y hoy se encuentra en el Museo de San Diego, de tamaño natural y pintada en tabla, es muy semejante en factura, dibujo y colorido, a la Asunción de Maria: el rostro del Señor tiene marcado parecido con la Santa Faz, y las figuras de la parte inferior ofrecen gran analogía con las de la Asunción, marcándose, una vez. más, el contraste de la parte ideal con la real de la composición: el resplandor en forma de almendra que circunda la figura del Salvador hace aún más densa la penumbra en que se encuentran los atónitos sayones. ${ }^{11}$

Ahora bien, en el número once de la serie de Pinturas Coloniales, que por los años de 1935 y 1936 publicaba la Cervecería Cuauhtémoc, apareció una semblanza de Miguel Jerónimo Zendejas, escrita por el señor Jorge Cuesta; pero la ilustración que la acompañaba -un San Jerónimo- de ninguna manera podía corresponder a dicho artista, pintor poblano menos que mediocre, sino que acusaba todas las características de Alonso López de Herrera. En la Angelópolis pudimos examinar detenidamente el original, que era propiedad particular de don Manuel Larre, director del Museo de Puebla, y encontramos desde luego que lo que se reprodujo era solamente un fragmento, puesto que, en la pintura original, a la izquierda del santo, se ven representados su oratorio, el león echado y los demás atributos de este Padre de la Iglesia. Desgraciadamente, esta parte de la pintura estaba doblada hacia atrás del bastidor y toda ella se encontraba en bastante mal estado de conservación; pero los libros, la mesa, el sillón y demás accesorios, recuerdan en el acto los del retrato de fray García Guerra, y los del Santo Tomás de Aquino, y existe la circunstancia de que, a primera

11 Según don Manuel $G$. Revilla, este cuadro perteneció en una época a don José García Rubí. Hablando de esta pintura y de la de la Asuncion, dice lo siguiente: "... hay que convenir en que una y otra son de la propia mano, pues que en las dos se notan evidentes caracteres comunes; el mismo dibujo, el mismo colorido, análogos escorzos, idéntico tratamiento de las cabelleras y unos mismos modelos que se advierte sirvieron en ambos cuadros." - El Arte en México. scgunda edición. Mé. xico, 1923, pp. 105 y 106. 
vista, los brazos del sillón parecen fuera de perspectiva, como sucede con la mesa de fray García Guerra. Pero los paños, el escorzo y el dibujo de las manos revelan inmediatamente al "divino Herrera". Alonso López de Herrera fue un verdadero maestro en el dificilísimo arte del escorzo, como lo atestiguan principalmente su Asunción de la Virgen, su Resurrección del Señor y su Santa Teresa de Jesús; y el único pintor virreinal que supo pintar manos con propiedad. Ni los Echave, ni los Juárez, ni aun Sebastián de Arteaga, pueden competir con él en este punto. Además, la mirada y la boca entreabierta del Santo son características de muchas obras de fray Alonso López de Herrera. Así las muestran Santa Teresa, San Agustin, Santo Domingo y los Apóstoles de la Asunción. Pero, sobre todo, las manos son inconfundibles. 12

En el número 15 de la Revista de Indias (Madrid, 1944), el historiador de arte, don Diego Angulo Iñ́guez, dio a conocer, en fotograbado un cuadro de la Anunciación, firmado por López de Herrera, lo que hizo recordar a don Manuel Toussaint, que él tenía la fotografía de otro del mismo tema, y al compararlos, encontró que éste era muy superior al que publicó Angulo, cosa que, en nuestra opinión, demuestra una vez más que López de Herrera acostumbraba mejorar, por decirlo así, la primera versión de muchos de sus cuadros. ${ }^{13}$

El mismo Toussaint se inclinaba a creer que una "tabla con un San Agustín escribiendo", que figuraba en la colección de don Salvador Ugarte era obra de López de Herrera; y es muy probable que, andando el tiempo, aparezcan otras obras atribuibles al pincel de aquel eminente pintor mexicano que fue apellidado en su tiempo, como en España Luis Morales, el divino Herrera.

12 Véase nuestro artículo Herrera, no Zendejas, publicado en "Excélsior", México, 6 de marzo de 1936.

13 Toussaint. Artículo citado. 